\title{
Current practices of adjunctive therapy for pertussis at six Canadian tertiary care pediatric hospitals
}

\author{
Christopher T Naugler MD, Scott A Halperin MD
}

\begin{abstract}
CT Naugler, SA Halperin. Current practices of adjunctive therapy for pertussis at six Canadian tertiary care pediatric hospitals. Can J Infect Dis 1998;9(2):83-86.

OBJECTIVE: To document initial investigations and treatment used in the management of children hospitalized with pertussis.

DESIGN: Retrospective chart review encompassing admissions from January 1, 1991 to June 1, 1995.

SETTING: Six Canadian pediatric hospitals representing about $39 \%$ of the pediatric tertiary care beds in Canada.

PATIENTS: Four hundred and forty children who met the inclusion criterion of a primary admitting diagnosis of pertussis and who did not meet the exclusion criterion of nosocomially acquired pertussis or a prior admission for pertussis during the study period.

MAIN RESULTS: Most patients had cultures positive for Bordetella pertussis, although the proportion of positive tests varied widely among hospitals. Erythromycin was the most commonly used medication; however, only $47 \%$ of children received the recommended dosage. Salbutamol and corticosteroids were used most often in patients with reactive airways disease. Younger children and those with reactive airways disease had longer lengths of stay in hospital. CONCLUSIONS: Pertussis treatment varied widely among the six hospitals studied, and was often not consistent with current Canadian recommendations. The results will allow practitioners to place their practices in a national perspective and provide a baseline for further studies.
\end{abstract}

Key Words: Adjunctive therapy, Bordetella pertussis, Pertussis, Whooping cough

\section{Pratiques actuelles en matière de traitement d'appoint contre la coqueluche dans} six hôpitaux pédiatriques canadiens de soins tertiaires

OBJECTIF : Documenter les recherches initiales et le traitement utilisé chez des enfants hospitalisés pour coqueluche. MODÈLE : Étude des dossiers rétrospective des admissions entre le $1^{\text {er }}$ janvier 1991 et le $1^{\text {er }}$ juin 1995.

CONTEXTE : Six hôpitaux pédiatriques canadiens représentant environ $39 \%$ des lits de soins tertiaires pédiatriques au Canada.

PATIENTS : Quatre cent quarante enfants qui répondaient au critère d'inclusion 'diagnostic primaire de coqueluche à l'admission' et qui n'avaient pas contracté la coqueluche pendant leur hospitalisation et n'avaient pas été admis antérieurement pour coqueluche au cours de la période de l'étude (critères d'exclusion).

PRINCIPAUX RÉSULTATS : Chez la plupart des patients, on a procédé à des cultures pour Bordetella pertussis, mais la proportion de tests positifs a grandement varié d'un hôpital à l'autre. L'érythromycine a été le médicament le plus fréquemment utilisé. Toutefois, $47 \%$ seulement des enfants ont reçu la posologie recommandée. Le salbutamol et les corticostéroïdes ont été utilisés le plus souvent chez les patients dont la maladie respiratoire était réactionnelle. Les

voir page suivante

Departments of Pediatrics, Microbiology and Immunology, Dalhousie University, Halifax, Nova Scotia Correspondence and reprints: Dr Scott A Halperin, IWK Grace Health Centre, 5850 University Avenue, Halifax, Nova Scotia B3J 3 G9. Telephone 902-428-8141, fax 902-428-3232, e-mail shalperin@iwkgrace.ns.ca Received for publication March 24, 1997. Accepted June 3, 1997 
enfants plus jeunes et ceux dont la maladie respiratoire était réactionnelle ont séjourné plus longtemps à l'hôpital. CONCLUSION : Le traitement de la coqueluche a varié considérablement entre les six hôpitaux étudiés et concorde peu avec les recommandations canadiennes actuelles. Les résultats permettront aux médecins de comparer leurs pratiques aux normes nationales et serviront de base à d'autres études à venir.

$\mathrm{P}$ ertussis (whooping cough) results from infection with the Gram-negative bacillus Bordetella pertussis. Following an initial colonization of the respiratory tract cilia, susceptible individuals experience a catarrhal phase consisting of upper respiratory symptoms, followed one to two weeks later by a paroxysmal phase that may last for four to eight weeks (1). Symptoms of the paroxysmal stage may include coughing, whooping and vomiting. Pertussis is primarily a disease of young children, but adults are increasingly recognized as a reservoir for its spread (2). Although vaccines have significantly reduced the incidence of pertussis over the past 50 years, treatment of the potentially lethal paroxysmal stage remains a problem. Because children under six months of age are at the greatest risk of severe disease and death, particularly if they have not received their primary immunization series $(3,4)$, hospitalization has been recommended for all children under one year of age with pertussis (2). Management of this disease has included antimicrobial agents, salbutamol, corticosteroids and intravenous pertussis immune globulin, but there appears to be no treatment consensus. The purpose of this paper is to compare the treatment of children hospitalized with pertussis in six tertiary care hospitals in Canada.

\section{PATIENTS AND METHODS}

Data were collected by a chart review of all cases of pertussis hospitalized between January 1, 1991 and June 1, 1995 at six tertiary care pediatric hospitals (Table 1) representing about $39 \%$ of the pediatric tertiary care beds in Canada (5). The inclusion criterion was hospitalization during the study period with a primary admitting diagnosis of pertussis. Exclu- sion criterion was nosocomially acquired pertussis or a prior admission for pertussis during the study period.

Chart reviews were performed by medical record technicians or nurses at each location, using standardized data collection forms. The record reviews were performed by a single person at each location with the exception of the British Columbia's Children's Hospital, where two individuals performed the medical record reviews. Validity testing performed at the Izaak Walton Killam-Grace Health Centre showed that there was a concordance rate of $94 \%$ to $96 \%$ between data transcribed by the authors and data transcribed by medical records personnel (data not shown). Statistical analyses were performed using the software programs SAS 6.08 (SAS Institute Inc, North Carolina) and EPI Info 6.0 (Centers for Disease Control and Prevention, Atlanta, Georgia). Because preliminary analyses showed that few variables were normally distributed, nonparametric statistics were used throughout. Categorical variables were compared using $\chi^{2}$ tests, whereas continuous variables were compared using Kruskall-Wallis tests for two groups or Kruskall-Wallis one-way ANOVAs as appropriate. The study received appropriate approval for medical records reviews at each institution.

\section{RESULTS}

Data were obtained from the medical records of 440 children (Table 1); $52 \%$ were female, and the sex ratio did not differ among hospitals $(\mathrm{P}=0.667)$. The median age of patients ranged from 2.6 to 4.4 months, but there was no significant difference among hospitals $(\mathrm{P}=0.0582)$. Overall, $10 \%$ of children hospitalized for pertussis had a history of reactive air-

TABLE 1

Demographics of 440 children admitted to six tertiary care hospitals with a primary admission diagnosis of pertussis

\begin{tabular}{|c|c|c|c|c|c|c|}
\hline \multirow[b]{2}{*}{ Patient characteristic } & \multicolumn{6}{|c|}{ Hospital } \\
\hline & ACPGH & ВССH & CHCNA & CHEO & IWKGHC & WCH \\
\hline Patients (\% female) & $82(55)$ & $80(58)$ & $42(48)$ & $126(52)$ & $65(45)$ & $45(55)$ \\
\hline Number (\%) with reactive airways disease & $10(12)$ & $5(6)$ & $3(7)$ & $12(10)$ & $10(15)$ & $4(9)$ \\
\hline Number of Bordetella pertussis cultures taken (\% positive) & $78(45)$ & $78(92)$ & $36(63)$ & $117(21)$ & $60(50)$ & $36(44)$ \\
\hline Number (\%) requiring intensive care & $25(30)$ & $20(25)$ & $4(10)$ & $5(4)$ & $10(15)$ & $22(49)$ \\
\hline Median LOS in intensive care unit (days) & 6 & 6 & 4.5 & 4 & 1.5 & 3.5 \\
\hline Number (\%) with complete blood count taken on admission* & $59(72)$ & $68(85)$ & $30(71)$ & $97(77)$ & $38(58)$ & $40(89)$ \\
\hline Number (\%) receiving oxygen saturation monitoring* & $64(78)$ & $74(92.5 \%)$ & $40(95)$ & $104(83)$ & $42(65)$ & $31(69)$ \\
\hline
\end{tabular}

*Sample size does not total 440 because of missing values. ACPGH Alberta Children's Provincial General Hospital, Calgary, Alberta; BCCH British Columbia's Children's Hospital, Vancouver, British Columbia; CHCNA Children's Health Centre of Northern Alberta, Edmonton, Alberta; CHEO Children's Hospital of Eastern Ontario, Ottawa, Ontario; IWKGHC Izaak Walton Killam-Grace Health Centre, Halifax, Nova Scotia; WCH Winnipeg Children's Hospital, Winnipeg, Manitoba 
TABLE 2

Erythromycin preparations, erythromycin dose and length of erythromycin course of $439 *$ children admitted to six tertiary care hospitals with a primary admission diagnosis of pertussis

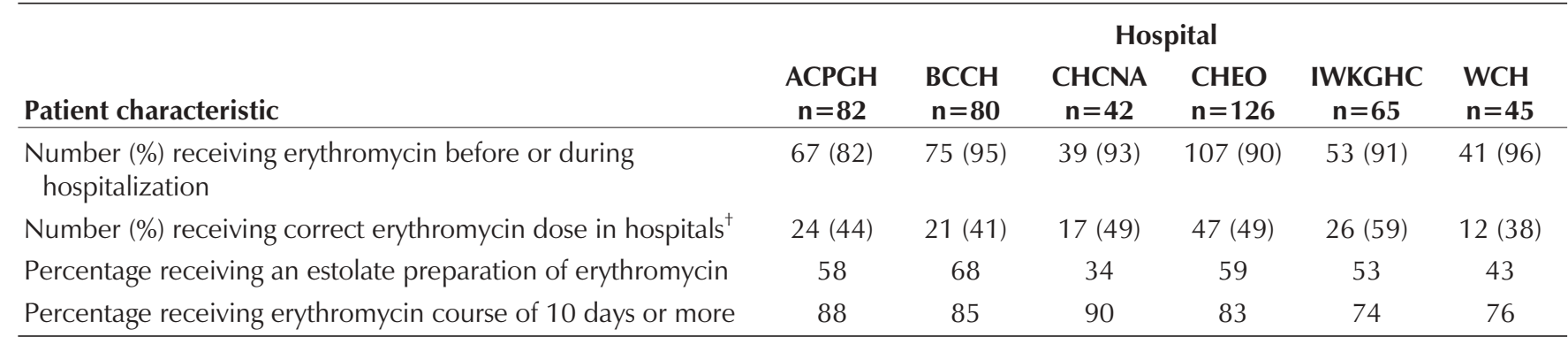

*Sample size does not total 440 because of missing values; ${ }^{\dagger} 40$ to $50 \mathrm{mg} / \mathrm{kg} /$ day to a maximum of $1 \mathrm{~g} /$ day. ACPGH Alberta Children's Provincial General Hospital, Calgary, Alberta; BCCH British Columbia's Children's Hospital, Vancouver, British Columbia; CHCNA Children's Health Centre of Northern Alberta, Edmonton, Alberta; CHEO Children's Hospital of Eastern Ontario, Ottawa, Ontario; IWKGHC Izaak Walton Killam-Grace Health Centre, Halifax, Nova Scotia; WCH Winnipeg Children's Hospital, Winnipeg, Manitoba

TABLE 3

Selected nonantibiotic treatment given to $\mathbf{4 4 0}$ children admitted to six tertiary care hospitals with a primary admission diagnosis of pertussis

\begin{tabular}{|c|c|c|c|c|c|c|}
\hline \multirow[b]{2}{*}{ Patient characteristic } & \multicolumn{6}{|c|}{ Hospital } \\
\hline & $\begin{array}{c}\text { ACPGH } \\
n=82\end{array}$ & $\begin{array}{l}\mathrm{BCCH} \\
\mathrm{n}=80\end{array}$ & $\begin{array}{c}\text { CHCNA } \\
n=42\end{array}$ & $\begin{array}{l}\text { CHEO } \\
n=126\end{array}$ & $\begin{array}{c}\text { IWKGHC } \\
n=65\end{array}$ & $\begin{array}{l}\text { WCH } \\
\mathrm{n}=45\end{array}$ \\
\hline $\begin{array}{l}\text { Number (\%) receiving inhaled salbutamol (excluding children } \\
\text { with reactive airways disease) }\end{array}$ & $22(30)$ & $9(12)$ & $12(31)$ & $35(31)$ & $13(24)$ & $1(2)$ \\
\hline $\begin{array}{l}\text { Number (\%) receiving oral intravenous or inhaled } \\
\text { steroids (excluding children with reactive airways disease) }\end{array}$ & $9(12)$ & $1(1)$ & $7(18)$ & $4(4)$ & $3(5)$ & $0(0)$ \\
\hline Number (\%) receiving intravenous pertussis immune globulin & $0(0)$ & $0(0)$ & $0(0)$ & $0(0)$ & $8(12)$ & $0(0)$ \\
\hline
\end{tabular}

ways disease. These children were older (median age four years) than patients with no history of reactive airways disease (median age three months, $\mathrm{P}<0.0001$ ). Both the proportion of individuals with a $B$ pertussis culture taken during their admission and with a positive $B$ pertussis culture varied widely among hospitals ( $\mathrm{P}=0.0107$ and $\mathrm{P}<0.001$, respectively). Most children over two months of age had complete ageappropriate immunizations which did not differ among hospitals $(\mathrm{P}=0.064)$. Significant differences were found among centres for complete blood counts taken on admission $(\mathrm{P}=0.00248)$ and use of oxygen saturation monitoring $(\mathrm{P}<0.0001)$.

Most ( $82 \%$ to $96 \%$ ) patients received a course of erythromycin either before or during hospitalization (Table 2). Between $38 \%$ and $59 \%$ (mean $47 \%$ ) of children received the recommended dose (40 to $50 \mathrm{mg} / \mathrm{kg} /$ day to a maximum of $1 \mathrm{~g} /$ day [6]) $(\mathrm{P}=0.424)$. The most common dosing error was inadequate dosages in older children. The proportion of children who were prescribed a course of erythromycin at least as long as the recommended 10 days (6) varied from $74 \%$ to $90 \%$ (mean $83 \%, \mathrm{P}=0.43$ ). There was no difference in the proportion of pertussis culture-negative (78\%) and pertussis culture-positive children (85\%) who received a course of erythromycin for at least 10 days $(\mathrm{P}=0.14)$. There was wide variation $(49 \%$ to $100 \%)$ in the proportion of children receiving erythromycin estolate versus other erythromycin preparations $(\mathrm{P}<0.0001)$.

Excluding children with reactive airways disease, salbutamol and steroid (oral, intravenous or inhaled) use also varied widely (Table $3, \mathrm{P}=0.005$ and $\mathrm{P}<0.0001$, respectively). Finally, 12 children at the Izaak Walton Killam-Grace Health Centre participated in an ongoing study of the use of intravenous pertussis immune globulin.

Median length of stay varied from three days at the Children's Hospital of Eastern Ontario to eight days at the Stollery Children's Health Centre $(\mathrm{P}<0.0001$, Table 1$)$. The percentage of children who spent time in the intensive care unit (ICU) also varied significantly $(\mathrm{P}<0.0001)$. Of 86 children admitted to ICUs, 20 were placed on a ventilator at some point during their hospitalization. For all hospitals combined, there was no significant difference between the median length of stay of children with complete age-appropriate immunizations (three days) and children with incomplete age-appropriate immunizations (four days, $\mathrm{P}=0.0556$ ). Children under six months of age had a median length of stay of five days, while children six months and over had a median length of stay of three days $(\mathrm{P}<0.0001)$. Children with a history of reactive airways disease had a longer length of stay (five days) than children with no such history (three days; $\mathrm{P}=0.0048$ ). 


\section{DISCUSSION}

Although there were few differences in the characteristics of the children hospitalized with pertussis at the participating hospitals, there was substantial variability in their medical management. Initial laboratory investigations were similar, but the proportion of children with a positive $B$ pertussis culture varied dramatically among hospitals, perhaps due to differences in laboratories, sampling technique, prior exposure to antibiotics or variation in admission criteria.

However, the greatest variability demonstrated was related to drug therapy. Nearly all children received a course of erythromycin at some point during their illness, although only $47 \%$ received the recommended dose (6). Many children received a course of erythromycin shorter than the current recommended length of 10 days (6). The preparation of erythromycin used was also variable, with a range from $32 \%$ to $68 \%$ using the estolate form. Although definitive evidence is lacking, it has been proposed that the erythromycin estolate may be the preparation of choice for the treatment of pertussis (2).

Salbutamol was used commonly in children with reactive airways disease, but use varied in other children with pertussis. Early authors suggested a beneficial effect of salbutamol (7-10), although two later double-blind placebo controlled trials of salbutamol did not demonstrate a significant effect on the number of coughing spasms or the duration of illness $(11,12)$. Excluding children with reactive airways disease, there was limited and varying use of steroids among hospitals. In mouse models, betamethasone inhibits the effect of pertussis toxin, which may play a role in the pathophysiology of pertussis (13). In humans, oral prednisolone (14), betamethasone $(15,16)$ and hydrocortisone $(17,18)$ have been

\section{REFERENCES}

1. Pittman M. The concept of pertussis as a toxin-mediated disease. Pediatr Infect Dis J 1984;3:467-86.

2. Bass JW. Pertussis: current status of prevention and treatment. Pediatr Infect Dis J 1985;4:614-9.

3. Sutter RW, Cochi SL. Pertussis hospitalizations and mortality in the United States, 1985-1988. JAMA 1992;267:386-91.

4. Cherry JD, Brunell PA, Golden GS, Karzon DT. Report of the task force on pertussis and pertussis immunization - 1988. Pediatrics 1988;81:S939-84.

5. Canadian Hospital Association. Guide to Canadian Health Care Facilities 1994-1995. Ottawa, Ontario: Canadian Hospital Association Press, 1994.

6. National Advisory Committee on Immunization, Advisory Committee on Epidemiology, Canadian Paedriatric Society. Statement on management of persons exposed to pertussis and pertussis outbreak control. Can Commun Dis Rep 1994;20:193-9.

7. Pavesio D, Ponzone A. Salbutamol and pertussis. Lancet 1977;i:310-2.

8. Peltola H, Michelsson K. Efficacy of salbutamol in treatment of infant pertussis demonstrated by sound spectrum analysis. Lancet 1982;i:310-2.

9. Badr-El-Din MK, Aref GH, Kassem AS, Abdel-Monelm MA, Ammr Abbassy A. A beta-adrenergic stimulant, salbutamol, in the treatment of pertussis. J Trop Med Hyg 1976;79:218-9.

10. Pavesio D, Mora P, Levi P. First results with salbutamol in the treatment of pertussis. Minerva Pediatr 1979;31:901-5.

11. Krantz I, Norrby SR, Trollfors B. Salbutamol vs placebo for treatment of pertussis. Pediatr Infect Dis J 1985;4:638-40.

12. Mertsola J, Viljanen MK, Ruuskanen O. Salbutamol in the reported to be beneficial. However, because of small sample sizes, different drugs and varying dosage regimens, confirmatory studies are required to determine the efficacy of steroids in the management of pertussis. Other investigational therapies, such as intravenous pertussis immune globulin (19-21), require further demonstration of effectiveness before they can be widely recommended.

We found both similarities and differences in hospital utilization among the centres. Length of stay varied at all centres by age and underlying disease. The longer median length of stay in children under six months of age is likely a reflection of the morbidity and mortality caused by the infection in younger children $(3,4)$. Not surprisingly, children with reactive airways disease also had longer stays and were generally older, showing the increased morbidity of pertussis in this group of children. There was also substantial variation among hospitals in the proportion of patients admitted to an intensive care unit. These utilization differences may be attributed in part to referral bias, provincial variation in case definition (22) or differing criteria for discharge among hospitals.

In summary, this study demonstrated both similarities and striking differences in the management of pertussis in Canada. It is hoped that this study will allow practitioners to place their treatment practices in a national perspective and provide a baseline for future trials on the efficacy of various treatments.

ACKNOWLEDGEMENTS: This research was supported by an Izaak Walton Killam Children's Hospital research grant to the authors and Izaak Walton Killam Children's Hospital and Medical Research Council of Canada studentship grants to Christopher Naugler.

treatment of whooping cough. Scand J Infect Dis 1986;18:593-4.

13. Torre D, Quadrelli C, Pugliese A, Maggiolo F. Effect of betamethasone in lungs of mice treated with lymphosispromoting factor of Bordetella pertussis. J Infect Dis 1986;154:238-44.

14. Barrie H. Treatment of whooping cough. Lancet 1982;ii:830-1.

15. Torre D, Tambini R, Giulio F, Bonetta G. Treatment with steroids in children with pertussis. Pediatr Infect Dis J 1993;5:419-20.

16. Chandra H, Rao CS, Karan S, Mathur YC. Evaluation of betamethasone and isoniazid along with chloramphenical in the management of whooping cough. Indian Pediatr 1972;9:70-4.

17. Zoumboulakis D, Anagnostakis D, Albanis V, Matsaniotis N. Steroids in treatment of pertussis: a controlled clinical trial. Arch Dis Child 1973;48:51-4.

18. Roberts I, Gavin R, Lennon D. Randomized controlled trial of steroids in pertussis. Pediatr Infect Dis J 1993;11:982-3.

19. Granstrom M, Olinder-Nielsen AM, Holmbald P, Mark A, Hanngren K. Specific immunoglobin for treatment of whooping cough. Lancet 1991;338:1230-3.

20. Ichimaru T, Ohara Y, Hojo M, Miyazaki S, Harano K, Totoki T. Treatment of severe pertussis by administration of specific gamma globulin with high titers anti-toxin antibody. Acta Paediatr 1992;82:1076-8.

21. Bruss JB, Malley R, Parker JC, et al. Treatment of severe pertussis with intravenous pertussis immune globulin. Abstracts of the 33rd ICAAC, New Orleans, October 17-20, 1993. (Abst)

22. Pertussis Consensus Conference. Can Commun Dis Rep 1993;19:124-35. 


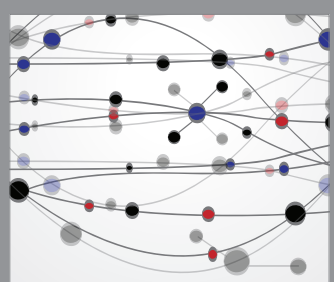

The Scientific World Journal
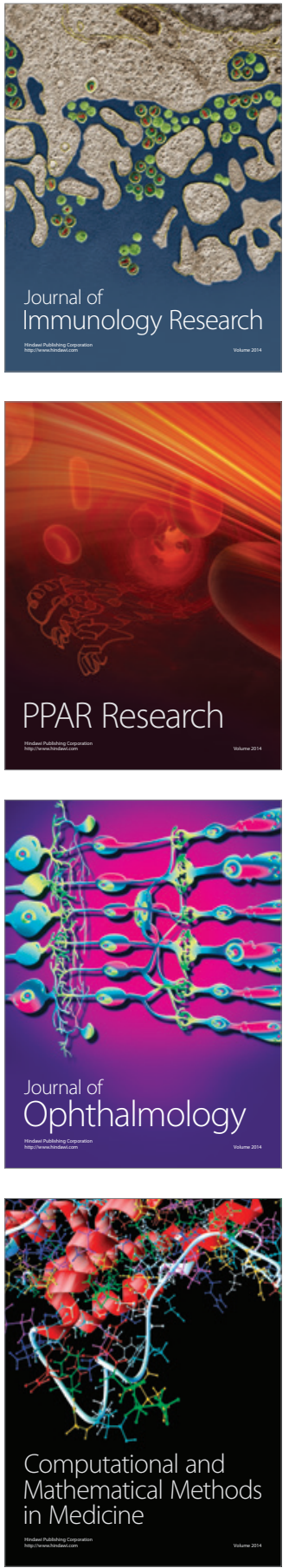

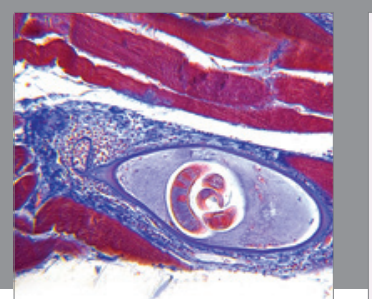

Gastroenterology Research and Practice

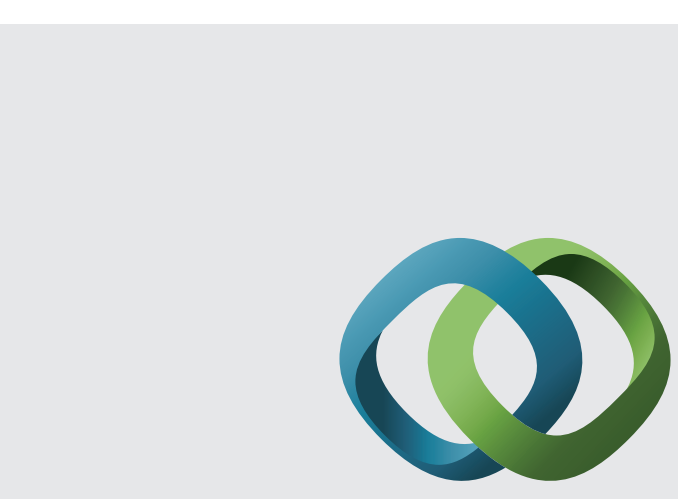

\section{Hindawi}

Submit your manuscripts at

http://www.hindawi.com
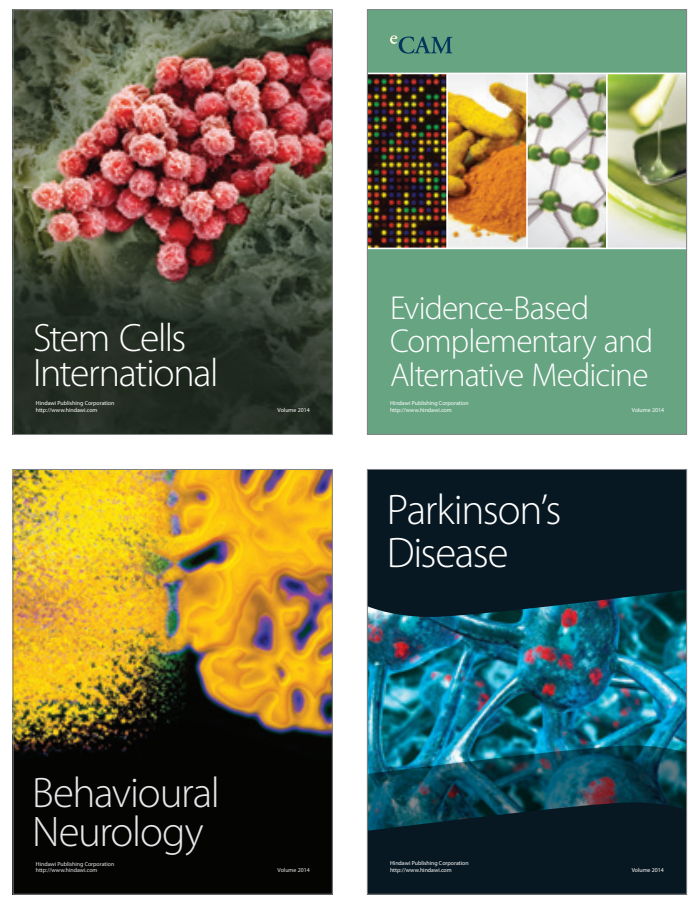
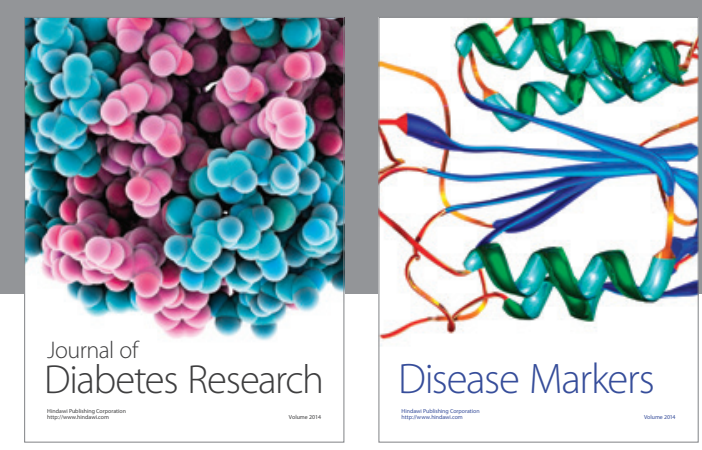

Disease Markers
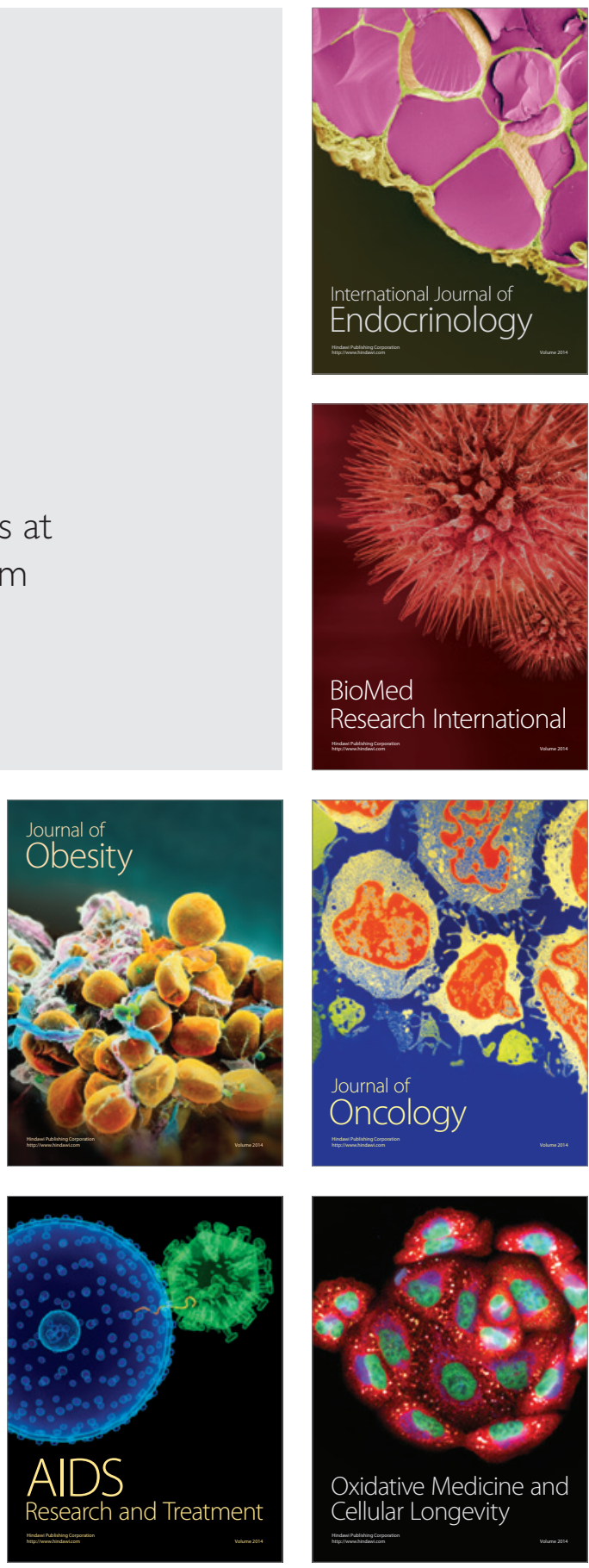